\title{
ELECTRE I Based Relevance Decision-Makers Feedback to the Location Selection of Distribution Centers
}

\author{
Maroi Agrebi, ${ }^{1,2,3}$ Mourad Abed, ${ }^{2}$ and Mohamed Nazih Omri ${ }^{3}$ \\ ${ }^{1}$ Faculty of Economic Sciences and Management, University of Sfax, Sfax, Tunisia \\ ${ }^{2}$ LAMIH UMR CNRS 8201, University of Valenciennes and Hainaut-Cambresis, Valenciennes, France \\ ${ }^{3}$ MARS UR11ES57, National School of Engineers of Sousse, University of Sousse, Sousse, Tunisia \\ Correspondence should be addressed to Maroi Agrebi; maroi.agrebi@univ-valenciennes.fr
}

Received 4 July 2016; Accepted 19 October 2016; Published 11 January 2017

Academic Editor: Zhi-Chun Li

Copyright (C) 2017 Maroi Agrebi et al. This is an open access article distributed under the Creative Commons Attribution License, which permits unrestricted use, distribution, and reproduction in any medium, provided the original work is properly cited.

\begin{abstract}
The location selection of distribution centers is one of the important strategies to optimize the logistics system. To solve this problem, under certain environment, this paper presents a new multicriteria decision-making method based on ELECTRE I. The proposed method helps decision-makers to select the best location from a given set of locations for implementing. After having identified decision-makers, the criteria, and the set of locations, the factors influencing the selection are analyzed in order to identify the best location. A sensitivity analysis is then performed to determine the influence of criteria weights on the selection decision. The strength of the proposed method is to incorporate decision-makers' preferences into the decision-making process. In addition, the proposed method considers both quantitative and qualitative criteria. Finally, the selected solution is validated by both tests of concordance and discordance simultaneously. A case study is provided to illustrate the proposed method.
\end{abstract}

\section{Introduction}

The location selection of logistics facilities like plants, distribution, and collection centers covers one of the main strategic issues of distribution system for company [1]. As a result of the importance and complexity of the logistics facility location, many methods have been developed to assist decisionmakers (DMs) to make a better decision. In fact, many issues emerge when it comes to facility location decision. First of all, the fact of having a committee of DMs, where each DM represents a company department (sustainable development, distribution, production, etc.) defending their objectives, could be the source of conflicts in the decision-making process. To be more specific, the incompatibility of the DMs' interests may cause these conflicts. As an example, locating the facility in somewhere close to the suppliers and the market is a good choice from the transportation point of view, whereas, from a production standpoint, a good location is somewhere close to the workforce and the raw materials. In addition, several criteria (like security [2], availability of acquirement material [3], human resources [4], etc.) should be taken into account forming one of the other possible conflict sources. Besides, the objectives of companies are often contradictory mostly in the case where companies wish to minimize an objective (e.g., minimization of distribution cost) and maximize another one (e.g., maximization of customer satisfaction).

In this paper, we are interested in answering the multicriteria decision-making (MCDM) problem for location selection of distribution centers (DCs) under certainty. Indeed, in city logistics the location of DCs has a significant impact on logistics optimization and transport activities. In fact, inefficiency and other negative aspects due to urban freight movement may affect these activities. As early as 1998, the European Commission reported that goods transport in cities represented $10 \%$ to $18 \%$ of road traffic and accounted for $40 \%$ of air pollution and noise emissions [5]. In 2012, about 44\% of goods transported in the European Union go by road [6].

The location selection of DCs may thus play an important role not only in minimizing traffic congestion and pollution [7], but also in decreasing transport cost $[8,9]$. Besides, the good locations of DCs may contribute in maximizing customers' satisfaction [9], as well as maximizing the acceptability by inhabitants, who live near the logistics platforms and are impacted by vehicles movements [7]. 
TABLE 1: The proposed methods for location selection of distribution centers under certainty.

\begin{tabular}{|c|c|c|}
\hline Methods & & Proposed by \\
\hline \multirow{2}{*}{ Multicriteria decision-making } & Method based on AHP and $k$-means method & Simić et al. [11] \\
\hline & Method based on REGIME & Chakraborty et al. [12] \\
\hline \multirow{10}{*}{$\begin{array}{l}\text { Metaheuristics for the multiobjective } \\
\text { decision-making }\end{array}$} & $\begin{array}{l}\text { Conceptual framework based on Adjusted Kuehn-Hamburger } \\
\text { model, method based on Grid model and ELECTRE }\end{array}$ & Ashayeri and Rongen [13] \\
\hline & Fixed-Charge Facility Location model & Nozick and Turnquist [14] \\
\hline & Genetic algorithm & $\begin{array}{l}\text { Fei et al. [15] } \\
\text { Zhang et al. [16] } \\
\text { Bai et al. [17] }\end{array}$ \\
\hline & Bilevel Programming model & Sun et al. [18] \\
\hline & Method based on Centre of Gravity principle & Van Thai and Grewal [19] \\
\hline & Binary Integer Programming & Chaiwuttisak et al. [20] \\
\hline & Particle Swarm Optimization algorithm & $\begin{array}{l}\text { Zeng et al. [21] } \\
\text { Hua et al. [22] } \\
\text { Wang et al. [23] }\end{array}$ \\
\hline & DNA Artificial Fish Swarm algorithm & Fei et al. [24] \\
\hline & Firefly algorithm & Hu et al. [25] \\
\hline & Method based on the Genetic algorithm and AHP & Ji and Huailin [26] \\
\hline \multirow{5}{*}{$\begin{array}{l}\text { Multiobjective combinatorial } \\
\text { optimization }\end{array}$} & Nonlinear Integer Programming & Avittathur et al. [27] \\
\hline & Branch and Bound & Crainic et al. [9] \\
\hline & $\begin{array}{l}\text { Method based on Exact Algorithm integrating the Adaptive } \\
\text { Epsilon-Constraint method, method based on Branch and Bound } \\
\text { and the Frank-Wolfe procedure }\end{array}$ & Gutjahr and Dzubur [28] \\
\hline & Mixed Integer Linear method & Tang et al. $[29,30]$ \\
\hline & Nonlinear Integer Bilevel Programming model & Yegane et al. [31] \\
\hline
\end{tabular}

To resolve this problem, this paper proposes a new MCDM method based on ELECTRE I [10]. The strength of the proposed method as compared to other ones is to incorporate DMs' preferences into the decision-making process. In addition, the proposed method considers both quantitative and qualitative criteria. Besides, it can take into account both desirable directions (Min and Max). Finally, the obtained solution is validated by both tests of concordance and discordance simultaneously.

The rest of this paper is organized as follows. The related literature is presented in Section 2. Section 3 presents a brief overview of MCDM methods and argues the choice of ELECTRE I. The proposed methodology is described in Section 4. Section 5 presents a numerical example and discusses the experimental results. The sensitivity analysis is shown in Section 6. Finally, the conclusion and further work are provided in the last section.

\section{Related Literature}

To arrange the survey of the problem of DCs' location selection in various aspects, we will divide it into three parts: nature of the problem, related methods, and discussion.

2.1. Nature of the Problem. Much of the literature has studied the problem of selecting DCs' location under a certain and a deterministic environment $[9,11,12,15-32]$. This kind of problem was characterized as static and deterministic, and parameters are known and fixed [33].

In practice, due to the complexity of the decision-making process and its ambiguity and vagueness related mainly to the human preferences and the anticipation of the different quantities and costs (e.g., the number of clients to serve and the fuel cost), many studies have been carried out on the problem under uncertainty [2-4, 8, 32-34]. In this category of problems, real data and information pertaining are unfixed numbers.

In this paper, we propose a new method to solve the problem of DCs' location selection under a certain environment. In the following subsection, we discuss the different methods that were proposed to solve this kind of problem.

2.2. Related Methods. In the literature, studies on problem of DCs' location selection under certainty have focused on three categories of solution techniques [35] (see Table 1):

(i) The multicriteria decision-making (MCDM)

(ii) The metaheuristics for the multiobjective decisionmaking (MMODM)

(iii) The multiobjective combinatorial optimization (MOCO)

2.2.1. The Multicriteria Decision-Making. In this category of methods, there are few methods that were proposed to solve 
TABLE 2: Comparison of some characteristics between methods proposed for location selection of distribution centers.

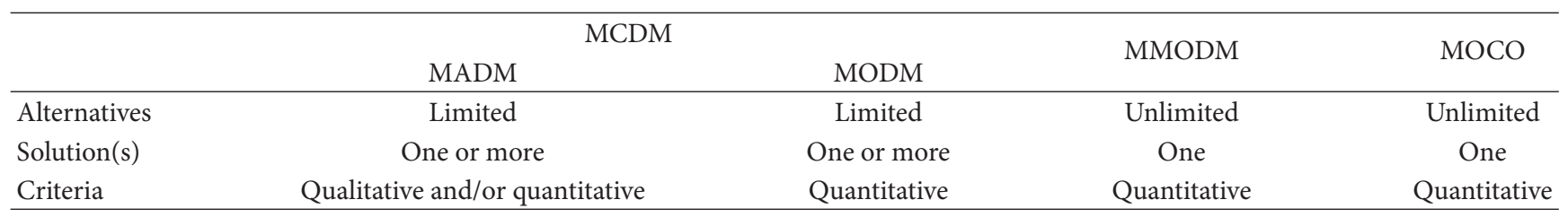

the problem in question. We cite the method based on Analytic Hierarchy Process (AHP) and $k$-means method [11] and the method based on REGIME [12].

The methods in this first category are used in the case where the number of predetermined alternatives are limited. According to Hekmatfar and Farahani [35], the set of predetermined alternatives satisfy each objective in a specified level. In addition, the DM selects the best solution (or solutions) among all alternatives according to the priority of each objective and the interaction between them.

2.2.2. The Metaheuristics for the Multiobjective DecisionMaking. In this category of methods, there is more work compared to the other two categories (cited above). Among these approaches, we cite the conceptual framework based on Adjusted Kuehn-Hamburger model, the method based on Grid model and ELECTRE [13], the Fixed-Charge Facility Location model [14], the Genetic algorithm [15-17], the Bilevel Programming model [18], the method based on Center of Gravity principle [19], the Binary Integer Programming [20], the Particle Swarm Optimization algorithm [21-23], the DNA Artificial Fish Swarm algorithm [24], the Firefly algorithm [25], the method based on the Genetic algorithm, and AHP [26].

The approaches in second category, according to Murata and Ishibuchi [36], attempt to convert the multiobjective problem into a single objective problem and optimize new single objective problem. According to Hekmatfar and Farahani [35], optimizing this single objective problem yields a single solution but the DMs need diverse options in the real condition. According to them [35], there are some classical methods that require knowing the optimal solution of each objective but acquiring this information is expensive and time consuming. In addition, it is difficult, especially in the case of nondeterministic situation, to choose weights for which these methods are dependent.

2.2.3. The Multiobjective Combinatorial Optimization. The proposed approaches in third category are the model for the Nonlinear Integer Programming [27], the Branch and Bound algorithm [9], the method based on Exact Algorithm integrating the Adaptive Epsilon-Constraint method, method based on Branch and Bound and the Frank-Wolfe procedure [28], the Mixed Integer Linear method [29, 30], and the Nonlinear Integer Bilevel Programming model [31].

These methods have been used to resolve the discrete multicriteria problems. Alternatives in this kind of problem are not explicitly known and are very large if countable.
2.3. Discussion. The main limitations of the methods cited above are as follows:

(i) Firstly, these methods do not take the DMs preferences into account, notably the role of their experience.

(ii) Secondly, they can deal with only quantitative criteria like transport costs, proximity to customers, and connectivity to multimodal transport. The consequence is that qualitative criteria, like congestion level, customer satisfaction, safety, and so forth, are unconsidered in the decision-making process.

(iii) Thirdly, they could not take into consideration both desirable directions (Min and Max).

To recap, the methods cited above are commonly used to solve multicriteria location problem of DCs. Nevertheless, they could not satisfy some cases. Table 2 presents a comparison of some characteristics between the three categories of solution techniques. In order to overcome the limitations cited above and to satisfy more the distribution centers location decisions requirements, we have proposed a new method based on ELECTRE I, which has not been used in the field of DCs location selection. The following section presents a brief overview of MCDM methods and argues the choice of ELECTRE I method.

\section{Multicriteria Decision-Making Methods: Overview}

MCDM methods are widely used to solve selection problems (e.g., selection of Enterprise Resource Planning (ERP) system [37], Cloud Service [38], Collaboration partner [39], and Agricultural scenario [40]). MCDM methods help the DMs to consider all criteria of the problem by using an explicit, rational, and efficient decision-making process. These methods are often categorized into multiobjective decisionmaking (MODM) methods and multiattributes decisionmaking (MADM) methods [41].

The MODM methods can require DMs to reach multiple noncommensurable objectives such as minimizing economic, environmental, and societal impacts. In practice, such methods, like Mixed Integer and Linear Programming, are quite complex to be used conveniently by operating managers [42]. In addition, those methods are unable to include qualitative factors [43].

The MADM methods can provide DMs with alternatives with several attributes attached to each decision. The attributes also are decision criteria that have to be considered simultaneously [42]. This category includes several methods: 
Analytic Network Process (ANP), Multiattribute Utility Theory (MAUT), Technique for Order Performance by Similarity to Ideal Solution (TOPSIS), and outranking Methods such as Preference Ranking Organization METHod for Enrichment Evaluations (PROMETHEE), ORESTE, MELCHIOR, TACTIC, Multicriterion Analysis of Preferences by means of Pairwise Actions and Criterion comparisons (MAPPAC), and ELimination and Choice Expressing REality (ELECTRE). However, these methods have limitations and drawbacks. Using MAUT method, usually, is quite difficult, impractical, or even impossible to obtain a mathematical representation of the DMs preferences in the form of utility functions [44-46]. With AHP and ANP methods, rank reversal and difficulty are observed when accommodating a great number of candidates. It is possible by using TOPSIS method to introduce two reference points. However, it does not consider the relative importance of the distances from these points. On the other hand, normalized values by vector normalization in the TOPSIS method may depend on the evaluation unit $[45,46]$.

In contrast to these methods, outranking methods allow incomparability between alternatives that can occur because of lack of information or inability of the DMs to compare alternatives [42, 47]. In addition, the outranking methods do not require as complete preference data [48]. Indifference and preference thresholds can provide meaningful and useful information when modeling the imperfect data [42].

ELECTRE and its different derivatives (ELECTRE I, ELECTRE II, ELECTRE III, ELECTRE IV, and ELECTRE TRI) are considered to be the most preferred methods [42] among several outranking methods like PROMETHEE and its derivatives (PROMETHEE I and II), ORESTE, QUALIFLES, MELCHIOR, MAPPACC, PRAGMA, and TACTIC. ELECTRE is considered as one of the best methods which take into account both desirable directions (Min and Max) [49]. The choice of one method among the ELECTRE family depends on the nature of the problem [50]. In fact, ELECTRE I is suitable for selection problems, whereas ELECTRE TRI is adapted to treat the problems of assignment and ELECTRE II, III, and IV to solve ranking problems.

To conclude, the ELECTRE I method is chosen to solve the problem of location selection for DCs, because it could improve the decision-making process by making it more realistic by firstly considering both quantitative and qualitative criteria, secondly taking criteria importance into account, thirdly including the DMs with their preferences into the decision-making process, and fourthly validating the selected solutions by both tests of concordance and discordance simultaneously.

\section{ELECTRE I Based Relevance Decision-Makers Feedback}

In this section, a new method based on ELECTRE I is presented to solve the selection problem of DCs location. The ELECTRE I method has been adapted in order to consider several DMs. The procedure is described as follows [51].

Step 1 (constitution of decision-makers' committee). This step consists in forming a committee of the DMs involved in the decision-making process from various departments (distribution, quality, sustainable development, etc.).

Step 2 (identification of potential locations). This step consists in identifying a set of potential locations of DCs based on sustainable freight regulations, DMs' preferences, and knowledge conditions of freight transportation. The potential locations are those that cater to the interest of all city stakeholders, that is, city residents, logistics operators, municipal administrations, and so forth [2].

Step 3 (selection of location criteria). This step consists in selecting criteria like security, transportation cost, and proximity to customers. Compared with the selected criteria, the alternatives will be evaluated.

Step 4 (importance weight assessment). This step consists, firstly, in assessing the importance weight by $K$ DMs using the scale measurement and secondly in calculating the weight of each criterion (see (1)).

$$
w_{j}=\frac{1}{K}\left[w_{j}^{1}+w_{j}^{2}+\cdots+w_{j}^{K}\right]
$$

Step 5 (alternatives rating assessment). This step consists in evaluating the rating of alternatives (see (2)) by $K$ DMs using the scale measurement for assessing ratings and then constructing the decision matrix.

$$
x_{i j}=\frac{1}{K}\left[x_{i j}^{1}+x_{i j}^{2}+\cdots+x_{i j}^{K}\right] .
$$

The format of decision matrix can be expressed as follows:

$$
\begin{aligned}
& D=\left[\begin{array}{cccc}
x_{11} & x_{12} & \cdots & x_{1 n} \\
x_{21} & x_{22} & \cdots & x_{2 n} \\
\cdot & \cdot & & \cdot \\
\cdot & \cdot & & \cdot \\
\cdot & \cdot & \cdots & \cdot \\
x_{m 1} & x_{m 2} & \cdots & x_{m n}
\end{array}\right] \\
& W=\left[\begin{array}{llll}
w_{1} & w_{2} & \cdots & w_{n}
\end{array}\right],
\end{aligned}
$$

where $x_{i j}, \forall i, j$ is the rating of alternative $A_{i}(i=1,2, \ldots, m)$ with respect to criterion $C_{j}$ and $w_{j}(j=1,2, \ldots, n)$ is the weight of criterion $C_{j}$.

Step 6 (determination of the relationship between alternatives). This step consists in determining the relationship between the alternatives with respect to each criterion. The pairwise comparison of the alternatives $\left(A_{i}\right.$ and $A_{k}$ where $k$ in $[i \cdots m]$ and $k \neq i)$ can be established as follows:

$$
J^{+}\left(A_{i}, A_{k}\right)=\left\{j \mid C_{j}\left(A_{i}\right)>C_{j}\left(A_{k}\right)\right\},
$$

where $J^{+}\left(A_{i}, A_{k}\right)$ is the set of criteria for which the alternative $A_{i}$ is preferred over $A_{k}$.

$$
J^{=}\left(A_{i}, A_{k}\right)=\left\{j \mid C_{j}\left(A_{i}\right)=C_{j}\left(A_{k}\right)\right\},
$$


where $J^{=}\left(A_{i}, A_{k}\right)$ is the set of criteria for which the alternative $A_{i}$ is equal in preference to alternative $A_{k}$.

$$
J^{-}\left(A_{i}, A_{k}\right)=\left\{j \mid C_{j}\left(A_{i}\right)<C_{j}\left(A_{k}\right)\right\},
$$

where $J^{-}\left(A_{i}, A_{k}\right)$ is the set of criteria for which the alternative $A_{k}$ is preferred over $A_{i}$.

Step 7 (conversion of the relationship between alternatives). This step consists in determining the sum of the criteria weights in each set of comparison:

$$
\begin{aligned}
& P^{+}\left(A_{i}, A_{k}\right)=\sum_{j} w_{j} \quad \forall j \in J^{+}\left(A_{i}, A_{k}\right), \\
& P^{=}\left(A_{i}, A_{k}\right)=\sum_{j} w_{j} \quad \forall j \in J^{=}\left(A_{i}, A_{k}\right), \\
& P^{-}\left(A_{i}, A_{k}\right)=\sum_{j} w_{j} \quad \forall j \in J^{-}\left(A_{i}, A_{k}\right) .
\end{aligned}
$$

$$
\begin{aligned}
& \text { (ii) Set of concordance: } \\
& \qquad J\left(A_{i}, A_{k}\right)=J^{+}\left(A_{i}, A_{k}\right) \cup J^{=}\left(A_{i}, A_{k}\right) . \\
& \text { (iii) Discordance index (DI): }
\end{aligned}
$$

$$
\mathrm{DI}_{i k}= \begin{cases}0 & \text { if } J^{-}\left(A_{i}, A_{k}\right)=\emptyset \\ \frac{1}{\partial_{j}} \times \max \left(C_{j}\left(A_{k}\right)-C_{j}\left(A_{i}\right)\right) & \text { where } j \in J^{-}\left(A_{i}, A_{k}\right), \text { otherwise, }\end{cases}
$$

where $\partial_{j}$ is the amplitude of the scale associated with criterion $j$. We note that $0 \leq \mathrm{DI}_{i k} \leq 1$.

Step 9 (filtering the alternatives). This step allows extracting, from all starting actions, the set of actions which respect (11). From this set, one action will finally be retained. It is one that outclasses more alternatives.

$$
\begin{gathered}
\mathrm{CI}_{i k} \geq \mathrm{ct} \\
\mathrm{DI}_{i k} \leq \mathrm{dt} \\
\mathbb{\mathbb { I }} \\
A_{i} S A_{k} .
\end{gathered}
$$

We note that $S$ is the outranking relation $\left(A_{i} S A_{k}\right.$ means that $A_{i}$ is at least as good as $A_{k}$ ).

\section{Experimental Results}

5.1. Decision Support System. For aiding the company to find an appropriate solution to its needs and specificities, the method described above has been used and was the nerve center of a decision support system (DSS) which we developed. The interface and the functionality of this DSS are implemented in Java 8.

Netbeans (https://netbeans.org/) has been selected as the appropriate development environment. Also, the system uses XML (https://www.w3.org/XML/) format for information transmission and storage (saving performed studies or projects). In addition, we made use of some APIs such as Apache POI (https://poi.apache.org/), JDBC (http://www.oracle.com/technetwork/java/javase/jdbc/index.html) in order to manage data, which may be extracted from excel files.

Users can generate data automatically based on a random generator or existing data source and manually. We note that the random generator is basically used for testing purpose.

5.2. Case Study. Let us assume that a company is interested in selecting a new DC location for implementation. The selection process of the best location is done by a committee of three DMs $D_{1}, D_{2}$, and $D_{3}$, the aim of which is to select a best location between three alternatives $A_{1}, A_{2}$, and $A_{3}$. To evaluate, the company considers six criteria, as shown in Table 3. The hierarchical structure of the selection process is illustrated by Figure 1.

The process selection is summarized in the following steps. First of all, the DMs $\left(D_{1}, D_{2}\right.$, and $\left.D_{3}\right)$ provided linguistic assessments for the criteria using the scale of weight importance (see Table 4). Likewise, the rating of alternatives is attributed by the DMs using the appropriate scale (see Table 5).

The assessments for the criteria and alternatives are detailed, respectively, in Tables 4 and 5 . We can see also in these tables (Tables 6 and 7), respectively, the weight of each criterion (calculated using (1)) and the rating of each alternative (calculated using (2)).

Next, using (4), (5), and (6), we have obtained the pairwise comparison of the alternatives $A_{1}, A_{2}$, and $A_{3}$. The relationship between alternatives is determined (as shown in 
TABLE 3: The criteria used for selection of a location of DCs.

\begin{tabular}{|c|c|c|c|}
\hline Criteria & Definition & Unit & Type \\
\hline Security $\left(C_{1}\right)$ & Security of the location from accidents & Qualitative & Benefit \\
\hline $\begin{array}{l}\text { Connectivity to multimodal transport } \\
\left(C_{2}\right)\end{array}$ & $\begin{array}{l}\text { Connectivity of the urban DCs with other modes } \\
\text { of transport }\end{array}$ & Quantitative & Benefit \\
\hline Costs $\left(C_{3}\right)$ & $\begin{array}{l}\text { Costs combining land cost, vehicle resources cost, } \\
\text { policy cost and taxes }\end{array}$ & Quantitative & Cost \\
\hline Proximity to customers $\left(C_{4}\right)$ & Distance of location to customer & Quantitative & Benefit \\
\hline Proximity to suppliers $\left(C_{5}\right)$ & Distance of location to suppliers & Quantitative & Benefit \\
\hline $\begin{array}{l}\text { Conformance to sustainable freight } \\
\text { regulations }\left(C_{6}\right)\end{array}$ & $\begin{array}{l}\text { Ability to conform to sustainable freight } \\
\text { restriction imposed by public authorities }\end{array}$ & Qualitative & Benefit \\
\hline
\end{tabular}

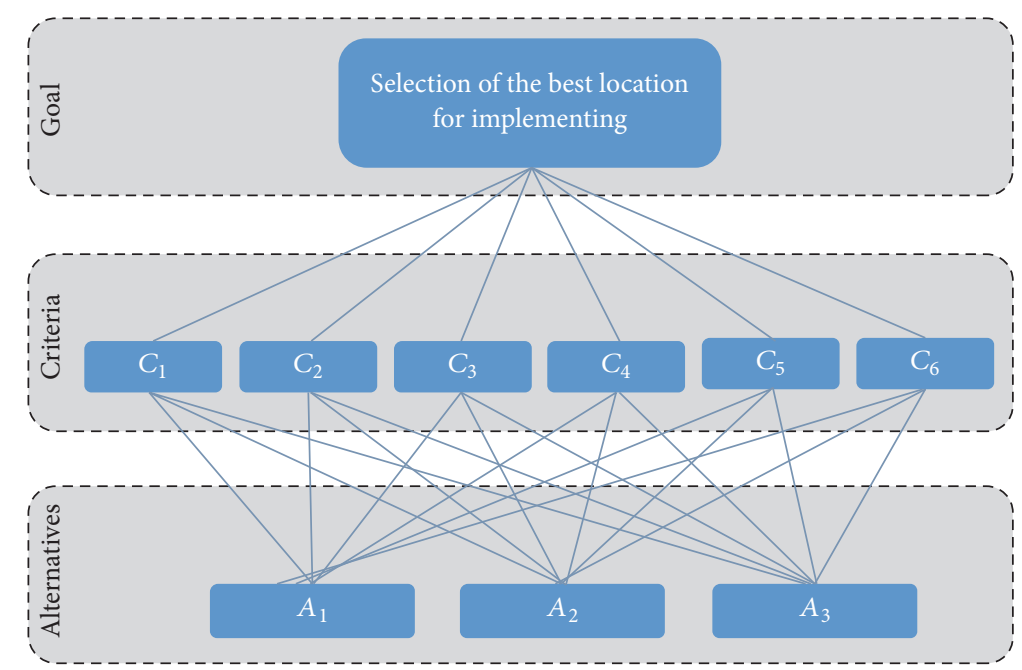

FIGURE 1: The hierarchical structure of the selection of DCs' location.

TABLE 4: Linguistic variables for the importance weight of each criterion.

\begin{tabular}{lc}
\hline Linguistic term & Weight \\
\hline Very low (VL) & {$[0-0,2[$} \\
Low $(\mathrm{L})$ & {$[0,2-0,4[$} \\
Medium $(\mathrm{M})$ & {$[0,4-0,6[$} \\
High $(\mathrm{H})$ & {$[0,6-0,8[$} \\
Very high $(\mathrm{H})$ & {$[0,8-1]$} \\
\hline
\end{tabular}

Tables 8, 9, and 10) with respect to the criteria. As an example, for $C_{1}$, the relationship between $A_{1}$ and $A_{2}$ is included in $J^{+}$ $\left(x_{11}>x_{12}\right)$.

Then, considering the relationship between the different alternatives and using (7), we determined for each set of comparison the sum of criteria weight. In Tables 11 and 12, we detailed the details of calculation.

Afterwards, the merge of the numerical values is obtained by calculating the coefficients of concordance $\mathrm{CI}_{i k}$ and the coefficients of discordance $\mathrm{DI}_{i k}$. For this step, we used (8)(10) as shown in Tables 11-14.

Finally, to filter the alternatives we have all necessary information to realize the test of concordance and the test of discordance. The threshold ct of concordance test is fixed to
TABLE 5: Linguistic variables for alternatives' rating.

\begin{tabular}{lc}
\hline Linguistic term & Rating \\
\hline Very poor (VP) & 1 \\
Poor (P) & 2 \\
Fair (F) & 3 \\
Good (G) & 4 \\
Very good (VG) & 5 \\
\hline
\end{tabular}

TABLE 6: The criteria weights attributed by DMs.

\begin{tabular}{lcccc}
\hline Criteria & \multicolumn{3}{c}{ Decision-makers } & Weight \\
& $D_{1}$ & $D_{2}$ & $D_{3}$ & \\
\hline$C_{1}$ & 0,099 & 0,251 & 0,218 & 0,189 \\
$C_{2}$ & 0,082 & 0,072 & 0,219 & 0,124 \\
$C_{3}$ & 0,323 & 0,212 & 0,184 & 0,239 \\
$C_{4}$ & 0,105 & 0,029 & 0,238 & 0,124 \\
$C_{5}$ & 0,068 & 0,233 & 0,049 & 0,116 \\
$C_{6}$ & 0,322 & 0,203 & 0,091 & 0,205 \\
\hline
\end{tabular}

0,8 . This test is satisfied if $\mathrm{CI}_{i k} \geq 0,8$. For the threshold $\mathrm{dt}$ of discordance test is fixed to 0,3 . Then, the test is satisfied if $\mathrm{DI}_{i k} \leq 0,3$. The $\mathrm{CI}_{i k}$, which satisfied the test of concordance, 
TABLE 7: The decision matrix.

\begin{tabular}{|c|c|c|c|c|c|}
\hline \multirow{2}{*}{ Criteria } & \multirow{2}{*}{ Alternatives } & \multicolumn{3}{|c|}{ Decision-makers } & \multirow{2}{*}{ Rating } \\
\hline & & $D_{1}$ & $D_{2}$ & $D_{3}$ & \\
\hline \multirow{3}{*}{$C_{1}$} & $A_{1}$ & 3 & 3 & 2 & 2,667 \\
\hline & $A_{2}$ & 4 & 1 & 1 & 2 \\
\hline & $A_{3}$ & 1 & 3 & 3 & 2,333 \\
\hline \multirow{3}{*}{$C_{2}$} & $A_{1}$ & 4 & 4 & 2 & 3,333 \\
\hline & $A_{2}$ & 1 & 2 & 3 & 2 \\
\hline & $A_{3}$ & 3 & 1 & 2 & 2 \\
\hline \multirow{3}{*}{$C_{3}$} & $A_{1}$ & 4 & 2 & 3 & 3 \\
\hline & $A_{2}$ & 1 & 4 & 2 & 2,333 \\
\hline & $A_{3}$ & 2 & 4 & 2 & 2,667 \\
\hline \multirow{3}{*}{$C_{4}$} & $A_{1}$ & 3 & 1 & 1 & 1,667 \\
\hline & $A_{2}$ & 1 & 1 & 4 & 2 \\
\hline & $A_{3}$ & 1 & 4 & 1 & 2 \\
\hline \multirow{3}{*}{$C_{5}$} & $A_{1}$ & 4 & 1 & 1 & 2 \\
\hline & $A_{2}$ & 4 & 4 & 4 & 4 \\
\hline & $A_{3}$ & 4 & 4 & 3 & 3,667 \\
\hline \multirow{3}{*}{$C_{6}$} & $A_{1}$ & 2 & 3 & 4 & 3 \\
\hline & $A_{2}$ & 1 & 2 & 3 & 2 \\
\hline & $A_{3}$ & 3 & 1 & 2 & 2 \\
\hline
\end{tabular}

TABLE 8: Summary of $J^{+}$.

\begin{tabular}{lccc}
\hline Alternatives & $A_{1}$ & $A_{2}$ & $A_{3}$ \\
\hline$A_{1}$ & - & $\{1,2,3,6\}$ & $\{1,2,3,6\}$ \\
$A_{2}$ & $\{4,5\}$ & - & $\{5\}$ \\
$A_{3}$ & $\{4,5\}$ & $\{1,3\}$ & - \\
\hline
\end{tabular}

TABLE 9: Summary of $J^{-}$.

\begin{tabular}{lccc}
\hline Alternatives & $A_{1}$ & $A_{2}$ & $A_{3}$ \\
\hline$A_{1}$ & - & $\{4,5\}$ & $\{4,5\}$ \\
$A_{2}$ & $\{1,2,3,6\}$ & - & $\{1,3\}$ \\
$A_{3}$ & $\{1,2,3,6\}$ & $\{5\}$ & - \\
\hline
\end{tabular}

TABLE 10: Summary of $J^{=}$.

\begin{tabular}{lccc}
\hline Alternatives & $A_{1}$ & $A_{2}$ & $A_{3}$ \\
\hline$A_{1}$ & - & $\emptyset$ & $\emptyset$ \\
$A_{2}$ & $\emptyset$ & - & $\{2,4,6\}$ \\
$A_{3}$ & $\emptyset$ & $\{2,4,6\}$ & - \\
\hline
\end{tabular}

TABLE 11: $P_{i k}^{+}$.

\begin{tabular}{lccc}
\hline Alternatives & $A_{1}$ & $A_{2}$ & $A_{3}$ \\
\hline$A_{1}$ & - & 0,757 & 0,757 \\
$A_{2}$ & 0,24 & - & 0,116 \\
$A_{3}$ & 0,24 & 0,428 & - \\
\hline
\end{tabular}

are $\mathrm{CI}_{32}$. The $\mathrm{DI}_{i k}$, which satisfied the test of discordance, are $\mathrm{DI}_{23}$ and $\mathrm{DI}_{32}$. Therefore, based on both concordance and discordance tests, we found that action $A_{3}$ upgraded action $A_{2}$ (as shown in Figure 2), because the relation of

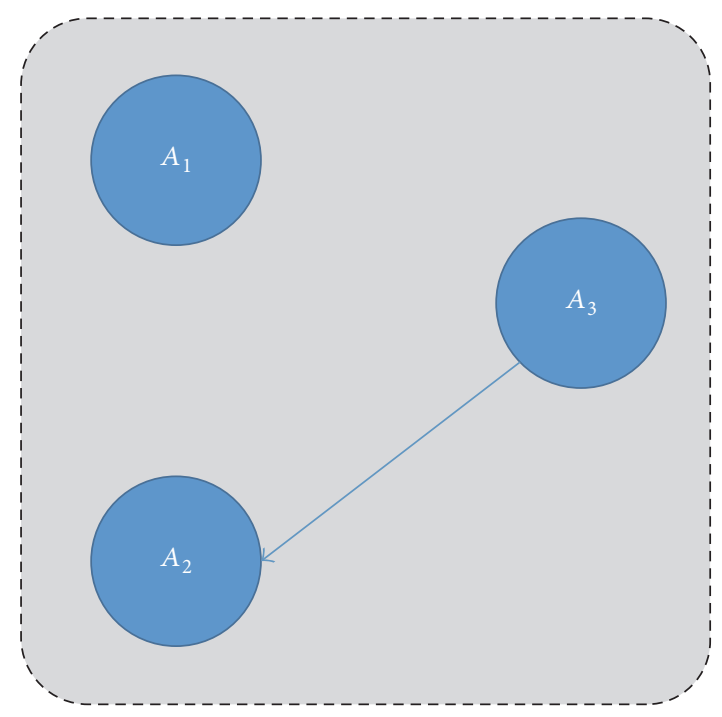

FIGURE 2: The outclass graph.

TABLE 12: $P_{i k}^{=}$.

\begin{tabular}{lccc}
\hline Alternatives & $A_{1}$ & $A_{2}$ & $A_{3}$ \\
\hline$A_{1}$ & - & $\emptyset$ & $\emptyset$ \\
$A_{2}$ & $\emptyset$ & - & 0,453 \\
$A_{3}$ & $\emptyset$ & 0,453 & - \\
\hline
\end{tabular}

TABLE 13: The matrix of concordance rates.

\begin{tabular}{lccc}
\hline Alternatives & $A_{1}$ & $A_{2}$ & $A_{3}$ \\
\hline$A_{1}$ & - & 0,759 & 0,759 \\
$A_{2}$ & 0,241 & - & 0,570 \\
$A_{3}$ & 0,241 & 0,883 & - \\
\hline
\end{tabular}

TABLE 14: The matrix of discordance rates.

\begin{tabular}{lccc}
\hline Alternatives & $A_{1}$ & $A_{2}$ & $A_{3}$ \\
\hline$A_{1}$ & - & 0,5 & 0,417 \\
$A_{2}$ & 0,333 & - & 0,083 \\
$A_{3}$ & 0,333 & 0,083 & - \\
\hline
\end{tabular}

concordance $\mathrm{CI}_{32}$ and the relation of discordance $\mathrm{DI}_{32}$ are verified. Then, we can infer that location $A_{3}$ is selected as the best location for implementing the new distribution center for the logistics company.

\section{Sensitivity Analysis}

6.1. Sensitivity Analysis Principles. This section consists in performing a sensitivity analysis based on the simulation of scenarios. The purpose is to verify the stability of the ranking of alternatives. It should be taken into account that the alternatives are influenced by the elements of the decision problem and, at the same time, the elements are influenced by the alternatives and other elements according to the weighted matrix [52]. 
TABLE 15: Experiments for sensitivity analysis.

\begin{tabular}{|c|c|c|}
\hline $\begin{array}{l}\text { Experiment } \\
\text { number }\end{array}$ & Description & $\begin{array}{l}\text { Selected } \\
\text { location }\end{array}$ \\
\hline 1 & All criteria weights $=0,2$ & $A_{3}$ \\
\hline 2 & All criteria weights $=0,4$ & $A_{3}$ \\
\hline 3 & All criteria weights $=0,6$ & $A_{3}$ \\
\hline 4 & All criteria weights $=0,8$ & $A_{3}$ \\
\hline 5 & All criteria weights $=1$ & $A_{3}$ \\
\hline \multirow{2}{*}{6} & Weight of criteria $1=1$ & \multirow{2}{*}{$A_{3}$} \\
\hline & Weight of remaining criteria $=0,2$ & \\
\hline \multirow{2}{*}{7} & Weight of criteria $2=1$ & \multirow{2}{*}{$A_{2}$ or $A_{3}$} \\
\hline & Weight of remaining criteria $=0,2$ & \\
\hline \multirow{2}{*}{8} & Weight of criteria $3=1$ & \multirow{2}{*}{$A_{3}$} \\
\hline & Weight of remaining criteria $=0,2$ & \\
\hline \multirow{2}{*}{9} & Weight of criteria $4=1$ & \multirow{2}{*}{$A_{2}$ or $A_{3}$} \\
\hline & Weight of remaining criteria $=0,2$ & \\
\hline \multirow{2}{*}{10} & Weight of criteria $5=1$ & \multirow{2}{*}{$A_{2}$} \\
\hline & Weight of remaining criteria $=0,2$ & \\
\hline \multirow{2}{*}{11} & Weight of criteria $6=1$ & \multirow{2}{*}{$A_{2}$ or $A_{3}$} \\
\hline & Weight of remaining criteria $=0,2$ & \\
\hline \multirow{2}{*}{12} & Weight of criteria $3=0,2$ & \multirow{2}{*}{$A_{3}$} \\
\hline & Weight of remaining criteria $=1$ & \\
\hline
\end{tabular}

In fact, this analysis addresses the question "How sensitive is the overall decision to small changes in the individual weights assigned during the pairwise comparison process?" [2]. This question can be answered by carrying out the sensitivity analysis; the criteria with the highest weight should be identified first. Subsequently, the change in the weights should be focused on criteria that have the most influence and those elements on which these criteria exert some influence.

6.2. Sensitivity Analysis Application. To investigate the impact of criteria weights on the location selection of DCs, we conducted a sensitivity analysis. Twelve experiments were conducted. The details of these experiments are presented in Table 15. It can be seen in Table 13 that, in the first five experiments, the weights of all criteria are set equal to 0,2 , $0,4,0,6,0,8$, and 1 . In experiments six to eleven, the weight of one criterion is set as the highest and the remaining are set to the lowest value. For example, in experiment eight, the cost category criteria $C_{3}$ have the highest weight equal to 1 , whereas the remaining criteria have weight equal to 0,2 . In experiment twelve, the weight of the cost category criteria $\left(C_{3}\right)$ is the lowest weight equal to 0,2 and the weights of the benefit category criteria $\left(C_{1}-C_{2}, C_{4}-C_{6}\right)$ are set as the highest weight equal to 1 .

Among the twelve scenarios, for eight experiments $(1,2$, $3,4,5,6,7$, and 12), $A_{3}$ has emerged as the best location. Contrariwise, in experiment $10, A_{2}$ has appeared as the winner. In the rest of experiments (7,9, and 11), both $A_{2}$ and $A_{3}$ have emerged as the best locations.

Therefore, we can say that the location decision is relatively insensitive to cost criteria weight. It can be seen where the weight of cost criteria $C_{3}$ is set as the highest or lowest; then the best solution is always $A_{3}$. In the opposite case, when the weights of benefit criteria $C_{1}$ and $C_{2}$ and from $C_{4}$ to $C_{6}$ are set as the highest (experiments 7, 9, 10, and 11), then the best solution is changed from $A_{3}$ to $A_{2}$ (experiment 10) and to both $A_{2}$ and $A_{3}$ in experiments 7, 9, and 11 .

\section{Conclusion and Future Work}

In this paper, we present a multicriteria decision-making method for location selection of DCs under a certain environment. The proposed method comprises nine steps. First of all, the DMs, the criteria, and the set of DCs' locations are determined. Then, influence factors of location selection are analyzed by means of proposed method based on ELECTRE I, and the best DC location is selected. Finally, sensitivity analysis is performed to determine the influence of criteria weights on the selection process.

The strength of our work is to incorporate decisionmakers' preferences into the decision-making process. In addition, the proposed method considers both quantitative and qualitative criteria. Finally, the selected solution is validated by both tests of concordance and discordance simultaneously.

The proposed method can be practically applied in different selection problems such as the selection of the best location (of hospitals, hotels, banks, etc.), suppliers, projects, and antibiotic. Therefore, it can be used by different domains like logistic, biomedical, automatic, and so forth. In our future work, we will take into account the following: firstly the ambiguity and vagueness related mainly to human preferences and secondly the real data and information which cannot be fixed in advance in such cases.

\section{Competing Interests}

The authors declare that there are no competing interests regarding the publication of this paper.

\section{References}

[1] A. Klose and A. Drexl, "Facility location models for distribution system design," European Journal of Operational Research, vol. 162, no. 1, pp. 4-29, 2005.

[2] A. Awasthi, S. S. Chauhan, and S. K. Goyal, "A multi-criteria decision making approach for location planning for urban distribution centers under uncertainty," Mathematical and Computer Modelling, vol. 53, no. 1-2, pp. 98-109, 2011.

[3] C.-T. Chen, "A fuzzy approach to select the location of the distribution center," Fuzzy Sets and Systems, vol. 118, no. 1, pp. 65-73, 2001.

[4] H.-S. Lee, "A fuzzy multi-criteria decision making model for the selection of the distribution center," in Advances in Natural Computation, L. Wang, K. Chen, and Y. S. Ong, Eds., vol. 3612 of Lecture Notes in Computer Science, pp. 1290-1299, Springer, Berlin, Germany, 2005.

[5] H. Koriath and W. Dietrich, Urban Goods Transport: COST 321Final Report of the Action, Office of the Official Publications of the European Community, Brussels, Belgium, 1998. 
[6] European Commission, Road Transport A Change of Gear, Publications Office of the European Union, Brussels, Belgium, 2012.

[7] O. Guyon, N. Absi, D. Feillet, and T. Garaix, "A modeling approach for locating logistics platforms for fast parcels delivery in urban areas," Procedia - Social and Behavioral Sciences, vol. 39, pp. 360-368, 2012.

[8] M. Hashim, L. Yao, A. H. Nadeem, M. Nazim, and M. Nazam, "Logistics distribution centers location problem under fuzzy environment," in Proceedings of the Seventh International Conference on Management Science and Engineering Management, pp. 927-939, Springer, Berlin, Germany, 2014.

[9] T. G. Crainic, N. Ricciardi, and G. Storchi, "Advanced freight transportation systems for congested urban areas," Transportation Research Part C: Emerging Technologies, vol. 12, no. 2, pp. 119-137, 2004.

[10] B. Roy, "Classement et choix en presence de points de vue multiples. Revue franaise d'automatique, d'informatique et de recherche oprationnelle," Recherche Operationnelle, vol. 2, no. 1, pp. 57-75, 1968.

[11] D. Simić, V. Ilin, I. Tanackov, V. Svirčević, and S. Simić, "A hybrid analytic hierarchy process for clustering and ranking best location for logistics distribution center," in Proceedings of the 10th International Conference on Hybrid Artificial Intelligent Systems (HAIS '15), pp. 477-488, Springer, Bilbao, Spain, June 2015.

[12] R. Chakraborty, A. Ray, and P. K. Dan, "Multi criteria decision making methods for location selection of distribution centers," International Journal of Industrial Engineering Computations, vol. 4, no. 4, pp. 491-504, 2013.

[13] J. Ashayeri and J. M. Rongen, "Central distribution in Europe: a multi-criteria approach to location selection," The International Journal of Logistics Management, vol. 8, no. 1, pp. 97-109, 1997.

[14] L. K. Nozick and M. A. Turnquist, "Integrating inventory impacts into a fixed-charge model for locating distribution centers," Transportation Research Part E: Logistics and Transportation Review, vol. 34, no. 3, pp. 173-186, 1998.

[15] C. Fei, C. Yan, and Z. Li-wei, "Model for selecting location of logistics distribution center," in Proceedings of the IEEE International Conference on Grey Systems and Intelligent Services (GSIS '07), pp. 1208-1211, November 2007.

[16] M. Zhang, H. Pang, S. Zhang, and R. Meng, "Selection of location for book distribution center based on genetic algorithm," Journal of Convergence Information Technology, vol. 8, no. 7, pp. 22-29, 2013.

[17] S.-Z. Bai, R.-Z. Meng, and S.-T. Zhang, "Research on location selection of dairy distribution center," in Proceedings of the International Conference on Logistics Systems and Intelligent Management (ICLSIM '10), vol. 2, pp. 898-901, IEEE, Harbin, China, January 2010.

[18] H. Sun, Z. Gao, and J. Wu, "A bi-level programming model and solution algorithm for the location of logistics distribution centers," Applied Mathematical Modelling, vol. 32, no. 4, pp. 610616, 2008.

[19] V. Van Thai and D. Grewal, "Selecting the location of distribution centre in logistics operations: a conceptual framework and case study," Asia Pacific Journal of Marketing and Logistics, vol. 17, no. 3, pp. 3-24, 2005.

[20] P. Chaiwuttisak, H. Smith, Y. Wu, C. Potts, T. Sakuldamrongpanich, and S. Pathomsiri, "Location of low-cost blood collection and distribution centres in Thailand," Operations Research for Health Care, vol. 9, pp. 7-15, 2016.
[21] Q. Zeng, C. Li, X. Wu et al., "Location selection of multiple logistics distribution center based on particle swarm optimization," in Intelligent Computing Theories and Application, D.-S. Huang, V. Bevilacqua, and P. Premaratne, Eds., vol. 9771 of Lecture Notes in Computer Science, pp. 651-658, Springer, New York, NY, USA, 2016.

[22] X. Hua, X. Hu, and W. Yuan, "Research optimization on logistics distribution center location based on adaptive particle swarm algorithm," Optik-International Journal for Light and Electron Optics, vol. 127, no. 20, pp. 8443-8450, 2016.

[23] Q. Wang, J. S. Duanmu, and L. Xu, "Selection of distribution center's location based on particle swarm optimization in military logistics," Computer Engineering and Design, vol. 30, no. 15, pp. 3597-3599, 2009.

[24] T. Fei, L. Zhang, Y. Sun, L. Chen, and H. Ren, "The location selection of distribution centre based on DNA artificial fish swarm algorithm," Journal of Computational and Theoretical Nanoscience, vol. 13, no. 2, pp. 1406-1414, 2016.

[25] W. Hu, Y. Hou, L. Tian, and Y. Li, "Selection of logistics distribution center location for SDN enterprises," Journal of Management Analytics, vol. 2, no. 3, pp. 202-215, 2015.

[26] L. Ji and D. Huailin, "Research on logistics distribution center location problem based on genetic algorithm and AHP," in Proceedings of the 4th International Conference on Computer Science \& Education (ICCSE '09), pp. 213-217, IEEE, Nanning, China, July 2009.

[27] B. Avittathur, J. Shah, and O. K. Gupta, "Distribution centre location modelling for differential sales tax structure," European Journal of Operational Research, vol. 162, no. 1, pp. 191-205, 2005.

[28] W. J. Gutjahr and N. Dzubur, "Bi-objective bilevel optimization of distribution center locations considering user equilibria," Transportation Research Part E: Logistics and Transportation Review, vol. 85, pp. 1-22, 2016.

[29] X. Tang, F. Lehud, and O. Pton, "Location of distribution centers in a multi-period collaborative distribution network," Electronic Notes in Discrete Mathematics, vol. 52, pp. 293-300, 2015.

[30] X. Tang, F. Lehud, and O. Pton, "Location of distribution centers in a multi-period collaborative distribution network," Electronic Notes in Discrete Mathematics, vol. 52, pp. 293-300, 2016.

[31] B. Y. Yegane, I. N. Kamalabadi, and H. Farughi, "A nonlinear integer Bi-level programming model for competitive facility location of distribution centers," International Journal of Engineering-Transactions B: Applications, vol. 29, no. 8, p. 1131, 2016.

[32] M. Agrebi, M. Abed, and M. N. Omri, "Urban distribution centers' location selection's problem: a survey," in Proceedings of the 4th IEEE International Conference on Advanced Logistics and Transport (IEEE ICALT '15), pp. 246-251, Valenciennes, France, May 2015.

[33] C. Rao, M. Goh, Y. Zhao, and J. Zheng, "Location selection of city logistics centers under sustainability," Transportation Research Part D: Transport and Environment, vol. 36, pp. 29-44, 2015.

[34] Y. H. Cheng and S. Y. Zhou, "Research of distribution center site selection based on fuzzy analytic hierarchy process," in Proceedings of the 22nd International Conference on Industrial Engineering and Engineering Management, pp. 335-342, Atlantis Press, 2016.

[35] M. Hekmatfar and R. Z. Farahani, Eds., Facility Location: Concepts, Models, Algorithms and Case Studies, Physica, 2009.

[36] T. Murata and H. Ishibuchi, "MOGA: multi-objective genetic algorithms," in Proceedings of the IEEE International Conference 
on Evolutionary Computation, vol. 1, p. 289, Perth, Australia, November 1995.

[37] B. Efe, "An integrated fuzzy multi criteria group decision making approach for ERP system selection," Applied Soft Computing Journal, vol. 38, pp. 106-117, 2016.

[38] S. Lee and K.-K. Seo, "A hybrid multi-criteria decision-making model for a cloud service selection problem using BSC, fuzzy delphi method and fuzzy AHP,' Wireless Personal Communications, vol. 86, no. 1, pp. 57-75, 2016.

[39] A. Awasthi, T. Adetiloye, and T. G. Crainic, "Collaboration partner selection for city logistics planning under municipal freight regulations," Applied Mathematical Modelling, vol. 40, no. 1, pp. 510-525, 2016.

[40] R. Javidi Sabbaghian, M. Zarghami, A. P. Nejadhashemi, M. B. Sharifi, M. R. Herman, and F. Daneshvar, "Application of risk-based multiple criteria decision analysis for selection of the best agricultural scenario for effective watershed management," Journal of Environmental Management, vol. 168, pp. 260-272, 2016.

[41] R. Z. Farahani, M. SteadieSeifi, and N. Asgari, "Multiple criteria facility location problems: a survey," Applied Mathematical Modelling, vol. 34, no. 7, pp. 1689-1709, 2010.

[42] A. Zandi and E. Roghanian, "Extension of Fuzzy ELECTRE based on VIKOR method," Computers and Industrial Engineering, vol. 66, no. 2, pp. 258-263, 2013.

[43] A. Sanayei, S. Farid Mousavi, and A. Yazdankhah, "Group decision making process for supplier selection with VIKOR under fuzzy environment," Expert Systems with Applications, vol. 37, no. 1, pp. 24-30, 2010.

[44] J. Malczewski and C. Rinner, Multicriteria Decision Analysis in Geographic Information Science, Springer, New York, NY, USA, 2015.

[45] S. Opricovic and G.-H. Tzeng, "Extended VIKOR method in comparison with outranking methods," European Journal of Operational Research, vol. 178, no. 2, pp. 514-529, 2007.

[46] S. Opricovic and G.-H. Tzeng, "Compromise solution by MCDM methods: a comparative analysis of VIKOR and TOPSIS," European Journal of Operational Research, vol. 156, no. 2, pp. 445-455, 2004.

[47] J. Siskos, "A way to deal with fuzzy preferences in multi-criteria decision problems," European Journal of Operational Research, vol. 10, no. 3, pp. 314-324, 1982.

[48] J. Kangas and A. Kangas, "Multiple criteria decision support in forest management-the approach, methods applied, and experiences gained," Forest Ecology and Management, vol. 207, no. 1-2, pp. 133-143, 2005.

[49] R. Z. Farahani and N. Asgari, "Combination of MCDM and covering techniques in a hierarchical model for facility location: a case study," European Journal of Operational Research, vol. 176, no. 3, pp. 1839-1858, 2007.

[50] M. G. Rogers, M. Bruen, and L. Y. Maystre, Electre and Decision Support: Methods and Applications in Engineering and Infrastructure Investment, Springer Science \& Business Media, Berlin, Germany, 2013.

[51] C. Collette and P. Siarry, Multiobjective Optimization, Éditions Eyrolles, London, UK, 2009.

[52] M. Molinos-Senante, T. Gómez, R. Caballero, F. HernándezSancho, and R. Sala-Garrido, "Assessment of wastewater treatment alternatives for small communities: an analytic network process approach," Science of the Total Environment, vol. 532, pp. 676-687, 2015. 


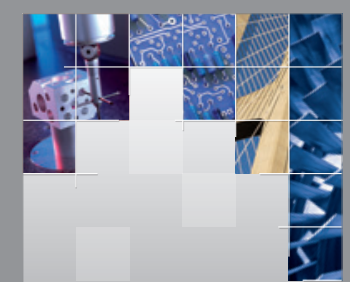

\section{Enfincering}
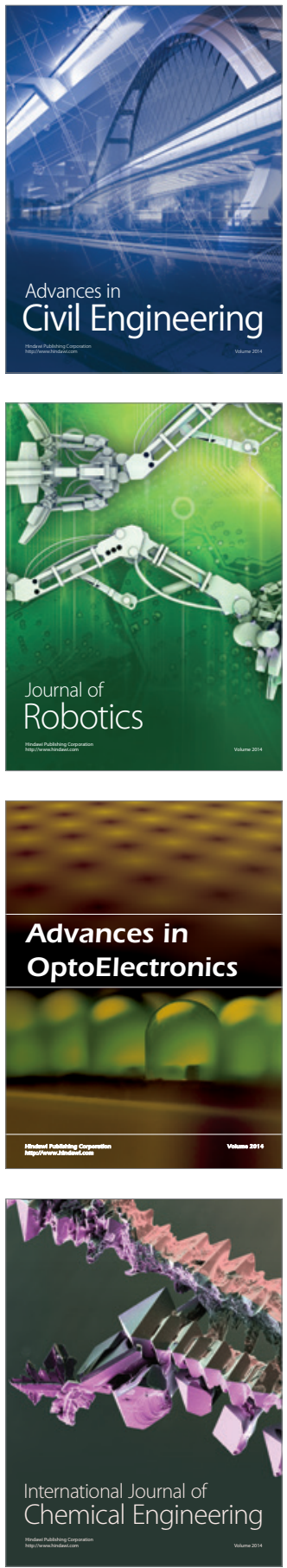

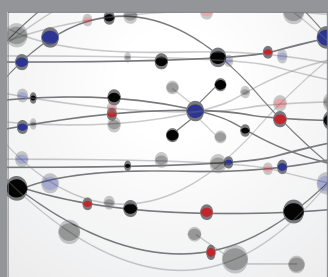

The Scientific World Journal

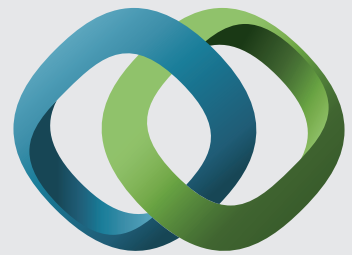

\section{Hindawi}

Submit your manuscripts at

https://www.hindawi.com
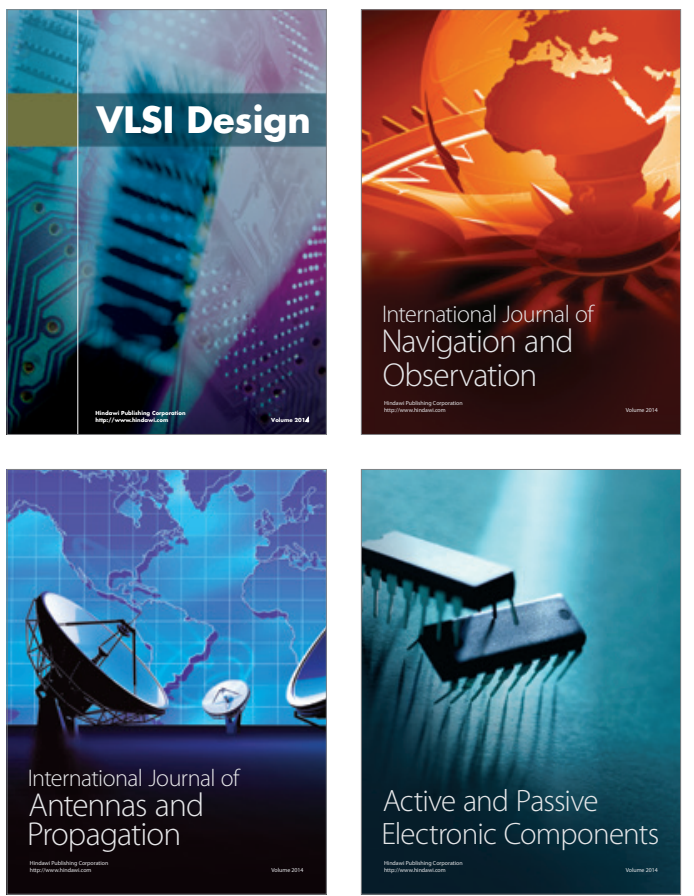
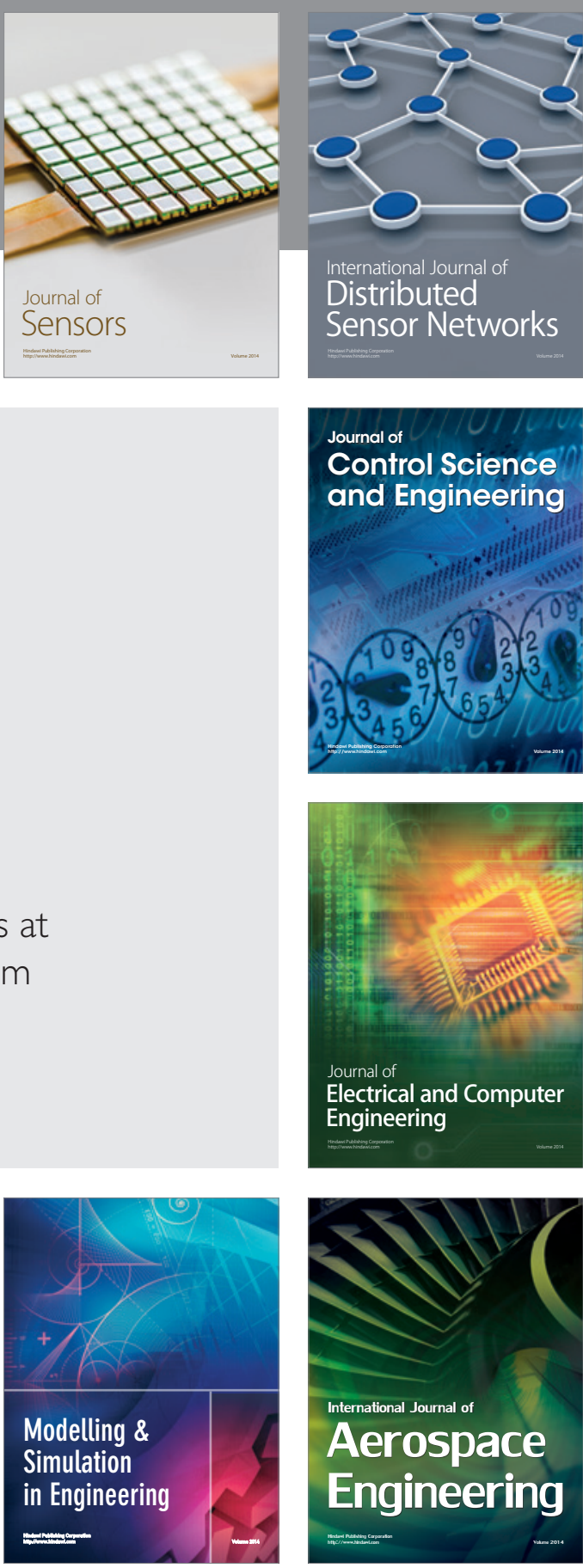

International Journal of

Distributed

Sensor Networks

$-$

Joumal of

Control Science

and Engineering
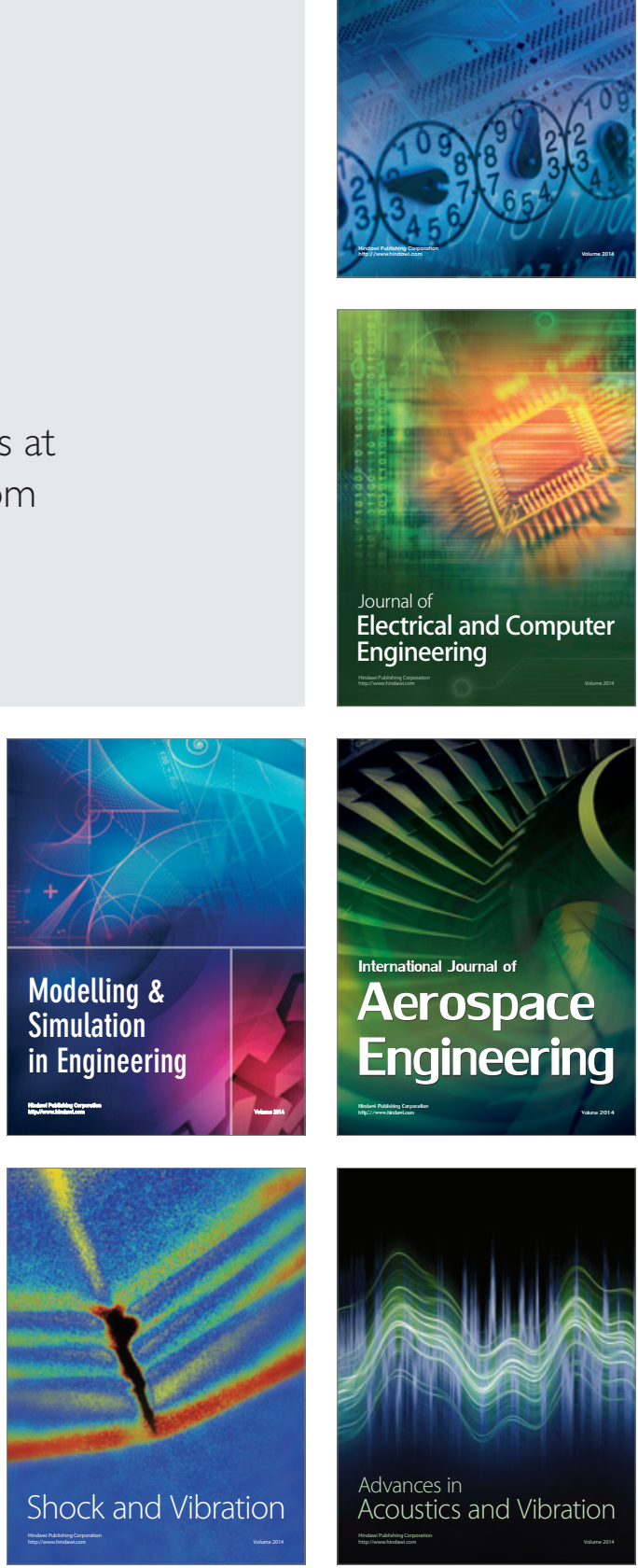